University of Montana

ScholarWorks at University of Montana

2-1994

\title{
The Composition and Social-Organization of Mixed-Species Flocks in a Tropical Deciduous Forest in Western Mexico
}

Richard L. Hutto

University of Montana - Missoula, hutto@mso.umt.edu

Follow this and additional works at: https://scholarworks.umt.edu/biosci_pubs

Part of the Biology Commons

Let us know how access to this document benefits you.

\section{Recommended Citation}

Hutto, Richard L., "The Composition and Social-Organization of Mixed-Species Flocks in a Tropical Deciduous Forest in Western Mexico" (1994). Biological Sciences Faculty Publications. 295.

https://scholarworks.umt.edu/biosci_pubs/295

This Article is brought to you for free and open access by the Biological Sciences at ScholarWorks at University of Montana. It has been accepted for inclusion in Biological Sciences Faculty Publications by an authorized administrator of ScholarWorks at University of Montana. For more information, please contact scholarworks@mso.umt.edu. 


\title{
THE COMPOSITION AND SOCIAL ORGANIZATION OF MIXED-SPECIES FLOCKS IN A TROPICAL DECIDUOUS FOREST IN WESTERN MEXICO ${ }^{1}$
}

\author{
RichaRd L. HuTto \\ Division of Biological Sciences, University of Montana, Missoula, MT 59812
}

\begin{abstract}
I recorded the flocking propensity of birds within a tropical deciduous forest in western Mexico during the nonbreeding season, and determined the species composition of 57 mixed-species, canopy insectivore flocks. Each of 27 canopy insectivore species present on the study area was observed foraging in mixed-species flocks on at least half of the occasions that it was detected on bird surveys. The proportion of flocks within which a given species was detected could be predicted on the basis of its index of abundance, as determined from independently derived point count data. Therefore, flocks are not comprised of a special subset of canopy insectivores; rather, the composition of flocks appears to be a product of whichever species co-occur within the foraging range of one or more nuclear species. No two canopy insectivore species were negatively associated among flocks, but 40 of 210 possible pairs (19\%) were significantly positively associated.

Two long-distance migratory species (Nashville Warbler [Vermivora ruficapilla] and Bluegray Gnatcatcher [Polioptila caerulea]) shared features that characterize nuclear species, thereby constituting one of the first recorded instances where nonresident species play such a role. Five of the more common flocking species were equally likely to have a foraging neighbor nearby $(<3 \mathrm{~m}$ away), but the identity of that neighbor differed significantly among the five species. Specifically, the identity of close neighbors of the two nuclear species was a random subset of the species available, while the close associates of three attendant species were a nonrandom subset of (mostly) other attendant species. The independent associations among flocks, which characterize most species, and the observation that nuclear species were not close neighbors more than expected for any of three attendant species suggests that foraging enhancement is not the principal benefit that attendant species derive from flocking.
\end{abstract}

Key words: Mixed-species flocks; spatial association; Neotropical migrant; migratory birds; nuclear species, Mexico; tropical deciduous forest.

\section{INTRODUCTION}

Throughout the world, insectivorous birds commonly forage in mixed-species flocks during the nonbreeding season (Rand 1954, Moynihan 1962). The most speciose flocks are composed of forest-canopy insectivores, and may regularly involve 20 or more species (Munn and Terborgh 1979; Hutto 1980, 1987). Two principal selective advantages are thought to favor the evolution of mixed-species flocking behavior: decreased predation and increased foraging efficiency (see reviews in Morse 1977, Powell 1985). Although the increased conspicuousness of flocking birds could offset any advantage they might gain through early detection of an approaching predator, that possibility is unlikely because an element of surprise is essential for a successful attack (Lindström 1989). In fact, the available data 1993. (reviewed in Powell 1985) suggest that flocking birds suffer relatively low predation risk because of the increased probability that an approaching predator will be detected.

Foraging benefits may accrue to a flocking bird because: (1) it can use information or protection provided by flockmates to exploit foraging locations, foraging tactics, or food types that it would not use otherwise (Krebs 1973, Valburg 1992); or (2) it can spend less time scanning for predators (Popp 1988, Elgar 1989), which provides additional time that can be devoted to otherwise similar foraging methods (but see Petit and Bildstein 1987). Alternatively, flocking species may experience reduced foraging efficiencies because of adjustments in movement patterns that are required either to stay with a flock, or to minimize competition for food (Jones 1977; Lima 1985; Petit and Bildstein 1987; Hogstad 1988b, 1989; Hutto 1988).

To resolve whether participants experience foraging-related costs or benefits when flocking, 
we need to devote more attention to testing predictions that necessarily follow from hypothesized feeding benefits and costs. For example, if the proposed benefit is an increase in the efficiency of finding and using patchily distributed food, then flock movement patterns should be irregular. In contrast with such a prediction, insectivorous bird flocks appear to move at a relatively constant rate through the woods (usually about $9 \mathrm{~cm} / \mathrm{sec}$; Morse 1970, Jones 1977, Powell 1979, Gaddis 1983, Hutto 1988). Feeding benefits could still come from an enhanced ability to copy the microhabitats or behaviors of neighbors, in which case we might expect nonrandom patterns of close association within flocks.

Unfortunately, with the exception of detailed studies of north temperate parid flocks (e.g., Lima 1985; Alatalo et al. 1987; Ekman 1987, 1989, 1990; Ekman and Hake 1988; Gustafsson, 1988; Hogstad 1988a, 1988b, 1989; Székely et al. 1989; Van Buskirk and Smith 1989), we still lack systematic studies of group memberships, movement patterns, and foraging behaviors of individual participants in many kinds of (especially tropical) mixed-species flocks (but see Greenberg 1984). Thus, it may be instructive to pay close attention to the composition of, and spatial organization within flocks because patterns of association both between and within flocks may enable us to better understand the costs and benefits associated with social foraging and, ultimately, the selective pressures leading to the evolution of mixed-species flocking behavior.

In this study, I determined the group membership of different mixed-species flocks within a lowland deciduous forest in western Mexico in winter to see if there were consistent patterns of association among species. Specifically, I focused on the canopy insectivores and tested (1) whether all insectivorous species were equally likely to participate, (2) whether some pairs of species were nonrandomly associated among flocks, and (3) whether the species showed nonrandom spatial associations within flocks.

\section{STUDY SITE AND METHODS}

I observed birds from mid-November to midDecember 1984, within the lowland tropical deciduous forest surrounding the Estación de Biología Chamela, Jalisco $\left(19^{\circ} 30^{\prime} \mathrm{N}, 105^{\circ} 03^{\prime} \mathrm{W}\right)$. The drought-deciduous vegetation of this area is dominated by plants in the families Leguminosae, Euphorbiaceae, and Sapindaceae. The forest was undisturbed except for the presence of about $10 \mathrm{~km}$ of access trails. Most trees were less than $10 \mathrm{~m}$ tall, and most had begun to lose their foliage, which facilitated bird observations.

Bird counts. I estimated the abundances of all landbird species through the use of point counts (Hutto et al. 1986). I positioned 70 count points along the permanent access trails so that each was at least $200 \mathrm{~m}$ from the next nearest point. At each point, I recorded the number of individuals of each species detected (excluding nocturnal and aerially-feeding species) within a $25-\mathrm{m}$ radius. I also recorded the presence of any additional species detected beyond $25 \mathrm{~m}$. Birds moving to within the $25 \mathrm{-m}$ radius during the count were recorded as detections within $25 \mathrm{~m}$. All counts were conducted between 07:00 and 10:30, and each lasted 10 min.

Social contexts of individuals. On days that I did not conduct formal point counts, I walked trail sections (a different section each time) and recorded the social context of each actively foraging bird I encountered. The bird was assumed to be foraging in a mixed-species flock if there was an individual of at least one other species located within $10 \mathrm{~m}$ of the subject bird, and the two or more birds appeared to be joining or following one another. The bird was assumed to be participating in a monospecific flock if all potential flockmates were of the same species. In the absence of leading and following movements between the subject bird and additional individuals, I categorized the bird as a solitary forager.

Flock compositions. Because the forest was impenetrable except through the use of access trails, it was difficult to determine flock composition reliably if the flock was detected some distance off a trail. To be confident that I had identified all participants of a flock, I restricted my observations to those flocks that were close enough for good visibility of participants. By traveling a different route each day, I was able to ensure that the samples were largely, if not wholly, independent.

Foraging neighbors. After flock compositions were determined, I spent additional time recording whether haphazardly selected focal individuals had "close" neighbors or not. The procedure was to select the first bird that came into view and determine whether any other individual was within about $3 \mathrm{~m}$ of the focal bird. If so, I noted the two (or more) species and recorded each as the others' close neighbor; if there was 


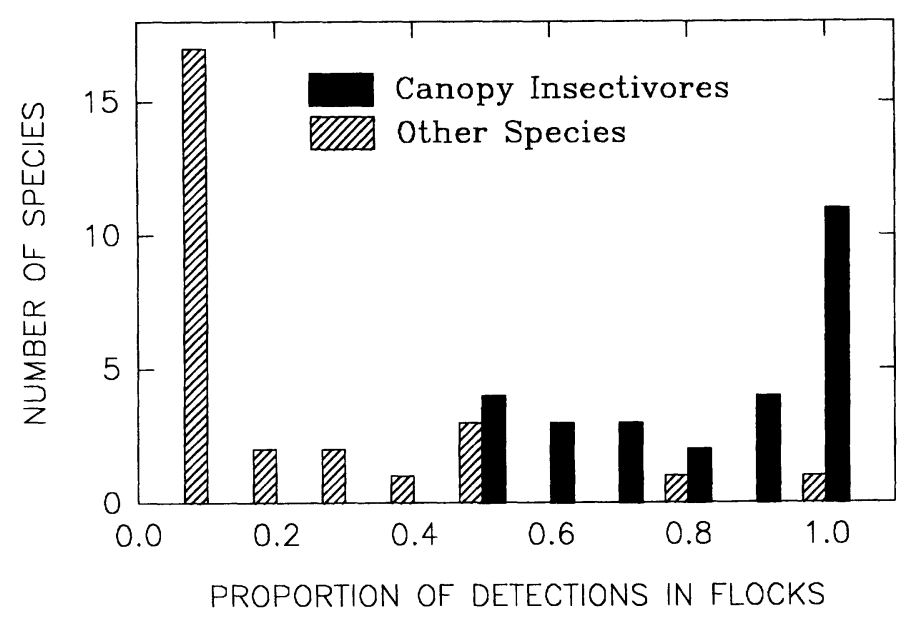

FIGURE 1. Histogram showing the number of canopy insectivore species and other species that occurred in each of 10 categories representing different proportions of time that a bird was observed foraging in a mixedspecies flock.

no close neighbor, I recorded that along with the species identity of the focal bird.

\section{RESULTS}

I recorded a total of 54 landbird species on 70 independent 10-min point counts; half (27) of those species are principally canopy insectivores (Table 1). All of the canopy insectivores were observed foraging in mixed-species flocks on at least half of the occasions that they were detected, and eight $(30 \%)$ of those species were never observed outside of heterospecific flocks (Table 1). In contrast, species using other feeding zones or diets were detected in flocks less often, if at all (Fig. 1). Many of the latter species (e.g., jays, caciques, doves, robins) foraged in mixed-species flocks on occasion, and one bush-insectivore species (Rosy Thrush-Tanager, Rhodinocichla rosea) was never detected outside a mixed-species flock. Nevertheless, no group of species appears to be as restricted as the canopy insectivores to foraging in mixed-species flocks.

I detected 66 flocks in my survey, and 57 of those flocks were close enough for me to be able to determine their membership with confidence. A total of 21 species was detected across all 57 flocks (Table 2), and the number of species detected in a single flock ranged from 2-17, and averaged 7.7 (Appendix I). Six canopy insectivore species [Pale-billed Woodpecker (Campephilus guatemalensis), Least Flycatcher (Empidonax minimus), Bright-rumped Attila (Attila spadiceus), Thick-billed Kingbird (Tyrannus crassirostris), Masked Tityra (Tityra semifasciata), and Black-capped Vireo (Vireo atricapillus)] were not detected in any of the 57 flocks, although they were observed as participants in other flocks. Each was relatively rare (recorded on three or fewer of the 70 point counts), so their absence from my sample of 57 flocks was not surprising. In fact, the proportion of mixed-species flocks within which any of the 27 canopy insectivore species was observed (Table 2) could be predicted on the basis of its index of abundance $(r=0.93, P<0.001$; Fig. 2$)$. This result is probably not an artifact of my ability to detect flocking birds more readily than non-flockers on point counts because (1) I had no special diffculty detecting non-flocking frugivores, omnivores, granivores, and nectarivores (Table 1); (2) my concentrated effort from a single point probably assured that most of the active birds were detected, whether in flocks or not; (3) I mistnetted 148 birds and never caught a species that went undetected on the counts. Thus, these canopy insectivore flocks do not appear to be comprised of a special subset of all canopy insectivores, as has been suggested to be the case for some Old World flocks (Croxall 1976, Herrera 1979, Greig-Smith 1978).

In addition to how frequently a species foraged in flocks (Table 1), I recorded the proportion of flocks occupied by each species (Table 2). The former is a measure of the "flocking propensity" of a bird species, while the latter is a measure of the "regularity of occurrence" of a species across 
TABLE 1. The feeding zone, diet, abundance, flocking propensity, and number of times each of 54 wintering landbird species was encountered in the tropical deciduous forest of Chamela, Jalisco.

\begin{tabular}{|c|c|c|c|c|c|c|}
\hline Species & $\begin{array}{l}\text { Mnemonic } \\
\text { code }\end{array}$ & Zone' $^{1}$ & Diet $^{2}$ & Abund $^{3}$ & $\mathrm{P}^{4}$ & $n^{5}$ \\
\hline Wagler's Chachalaca (Ortalis poliocephala) & $\mathrm{CHAC}$ & G & $\mathrm{O}$ & 14.3 & 0.00 & 17 \\
\hline Inca Dove (Columbina inca) & INDO & G & $\mathbf{S}$ & 0.0 & 0.28 & 18 \\
\hline Common Ground-Dove (Columbina passerina) & COGD & G & $\mathbf{S}$ & 1.4 & 0.40 & 10 \\
\hline White-tipped Dove (Leptotila verreauxi) & WTDO & $\mathrm{C}$ & $\mathrm{F}$ & 8.6 & 0.00 & 12 \\
\hline Orange-fronted Parakeet (Aratinga canicularis) & OFPA & $\mathrm{C}$ & $\mathrm{F}$ & 0.0 & 0.00 & 28 \\
\hline Lilac-crowned Parrot (Amazona finschi) & LCPA & $\mathrm{C}$ & $\mathrm{F}$ & 0.0 & 0.00 & 26 \\
\hline Squirrel Cuckoo (Piaya cayana) & SQCU & $\mathrm{C}$ & $\mathrm{O}$ & 2.9 & 0.00 & 9 \\
\hline Groove-billed Ani (Crotophaga sulcirostris) & GBAN & G & $\mathbf{S}$ & 0.0 & 0.00 & 5 \\
\hline Fork-tailed Emerald (Chlorostilbon canivetii) & FTEM & B & $\mathrm{N}$ & 10.0 & 0.00 & 8 \\
\hline Cinnamon Hummingbird (Amazilia rutila) & CIHU & B & $\mathrm{N}$ & 21.4 & 0.00 & 22 \\
\hline Citreoline Trogon (Trogon citreolus) & CITR & $\mathrm{C}$ & I & 7.1 & 0.64 & 14 \\
\hline Golden-cheeked Woodpecker (Melanerpes chrysogenys) & GCWO & $\mathrm{C}$ & I & 8.6 & 0.77 & 13 \\
\hline Pale-billed Woodpecker (Campephilus guatemalensis) & PBWO & $\mathrm{C}$ & I & 4.3 & 0.50 & 6 \\
\hline Ivory-billed Woodcreeper (Xiphorhynchus flavigaster) & IBWO & $\mathrm{C}$ & I & 7.1 & 0.82 & 11 \\
\hline Northern Beardless-Tyrannulet (Camptostoma imberbe) & NOBT & $\mathrm{C}$ & I & 17.1 & 1.00 & 22 \\
\hline Least Flycatcher (Empidonax minimus) & LEFL & $\mathrm{C}$ & I & 4.3 & 0.50 & 6 \\
\hline Western Flycatcher (Empidonax difficilis) & WEFL & $\mathrm{C}$ & I & 50.0 & 0.70 & 47 \\
\hline Bright-rumped Attila (Attila spadiceus) & BRAT & $\mathrm{C}$ & I & 1.4 & 0.56 & 9 \\
\hline Dusky-capped Flycatcher (Myiarchus tuberculifer) & DCFL & $\mathrm{C}$ & I & 25.7 & 0.92 & 39 \\
\hline Ash-throated Flycatcher (Myiarchus cinerascens) & ATFL & $\mathrm{C}$ & I & 31.4 & 0.87 & 23 \\
\hline Brown-crested Flycatcher (Myiarchus tyrannulus) & BCFL & $\mathrm{C}$ & I & 30.0 & 1.00 & 23 \\
\hline Flammulated Flycatcher (Deltarhynchus flammulatus) & FLFL & $\mathrm{C}$ & I & 0.0 & 0.67 & 6 \\
\hline Thick-billed Kingbird (Tyrannus crassirostris) & TBKI & $\mathrm{C}$ & I & 0.0 & 0.50 & 2 \\
\hline Rose-throated Becard (Pachyramphus aglaiae) & RTBE & $\mathrm{C}$ & I & 2.9 & 0.83 & 6 \\
\hline Masked Tityra (Tityra semifasciata) & MATI & $\mathrm{C}$ & I & 2.9 & 0.86 & 7 \\
\hline San Blas Jay (Cyanocorax sanblasianus) & SBJA & $\mathrm{C}$ & $\mathrm{O}$ & 7.1 & 0.80 & 10 \\
\hline Sinaloa Wren (Thryothorus sinaloa) & SIWR & B & I & 17.1 & 0.00 & 29 \\
\hline Happy Wren (Thryothorus felix) & HAWR & B & I & 8.6 & 0.00 & 17 \\
\hline White-bellied Wren (Uropsila leucogastra) & WBWR & B & I & 27.1 & 0.00 & 25 \\
\hline Blue-gray Gnatcatcher (Polioptila caerulea) & BGGN & $\mathrm{C}$ & I & 60.0 & 0.94 & 51 \\
\hline Swainson's Thrush (Catharus ustulatus) & SWTH & B & $\mathrm{F}$ & 2.9 & 0.17 & 12 \\
\hline White-throated Robin (Turdus assimilis) & WTRO & $\mathrm{C}$ & $\mathrm{F}$ & 1.4 & 0.20 & 5 \\
\hline Rufous-backed Robin (Turdus rufopalliatus) & RBRO & $\mathrm{C}$ & $\mathrm{F}$ & 4.3 & 0.50 & 6 \\
\hline Blue Mockingbird (Melanotis caerulescens) & BLMO & B & I & 1.4 & 0.00 & 8 \\
\hline Black-capped Vireo (Vireo atricapillus) & BCVI & $\mathrm{C}$ & I & 1.4 & 0.50 & 2 \\
\hline Solitary Vireo (Vireo solitarius) & SOVI & $\mathrm{C}$ & I & 7.1 & 1.00 & 21 \\
\hline Golden Vireo (Vireo hypochryseus) & GOVI & $\mathrm{C}$ & I & 2.9 & 1.00 & 4 \\
\hline Warbling Vireo (Vireo gilvus) & WAVI & $\mathrm{C}$ & I & 18.6 & 1.00 & 26 \\
\hline Nashville Warbler (Vermivora ruficapilla) & NAWA & $\mathrm{C}$ & I & 101.4 & 0.93 & 55 \\
\hline Tropical Parula (Parula pitiayumi) & TRPA & $\mathrm{C}$ & I & 27.1 & 1.00 & 37 \\
\hline Black-throated Gray Warbler (Dendroica nigrescens) & BTGW & $\mathrm{C}$ & I & 20.0 & 1.00 & 23 \\
\hline Black-and-white Warbler (Mniotilta varia) & BAWW & $\mathrm{C}$ & I & 5.7 & 1.00 & 19 \\
\hline Wilson's Warbler (Wilsonia pusilla) & WIWA & $\mathrm{C}$ & I & 47.1 & 0.58 & 48 \\
\hline Red-breasted Chat (Granatellus venustus) & $\mathrm{RBCH}$ & B & I & 0.0 & 0.00 & 5 \\
\hline Scrub Euphonia (Euphonia affinis) & SCEU & $\mathrm{C}$ & $\mathrm{F}$ & 2.9 & 0.50 & 2 \\
\hline Summer Tanager (Piranga rubra) & SUTA & $\mathrm{C}$ & I & 1.4 & 0.60 & 5 \\
\hline Grayish Saltator (Saltator coerulescens) & GRSA & G & $\mathbf{S}$ & 2.9 & 0.00 & 6 \\
\hline Rosy Thrush-Tanager (Rhodinocichla rosea) & ROTT & B & I & 1.4 & 1.00 & 3 \\
\hline Yellow Grosbeak (Pheucticus chrysopeplus) & YEGR & G & $\mathbf{S}$ & 1.4 & 0.25 & 8 \\
\hline Blue Bunting (Cyanocompsa parellina) & BLBU & G & $\mathbf{S}$ & 20.0 & 0.00 & 22 \\
\hline Varied Bunting (Passerina versicolor) & VABU & $\mathrm{G}$ & $\mathbf{S}$ & 8.6 & 0.00 & 12 \\
\hline Orange-breasted Bunting (Passerina leclancherii) & OBBU & G & $\mathbf{S}$ & 4.3 & 0.00 & 9 \\
\hline Streak-backed Oriole (Icterus pustulatus) & SBOR & $\mathrm{C}$ & I & 12.9 & 0.80 & 15 \\
\hline Yellow-winged Cacique (Cacicus melanicterus) & YWCA & $\mathrm{C}$ & $\mathrm{F}$ & 11.4 & 0.50 & 26 \\
\hline
\end{tabular}

' Based on my own observations; $\mathbf{G}=$ ground, $\mathbf{B}=$ bush-level, $\mathrm{C}=$ canopy-level.

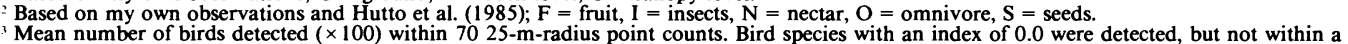
25-m radius.

${ }^{+}$Proportion of $(n)$ encounters with a species during which the individual was observed foraging with a mixed-species flock.

Proportion of $(n)$ encounters with a spec
Number of individuals encountered. 


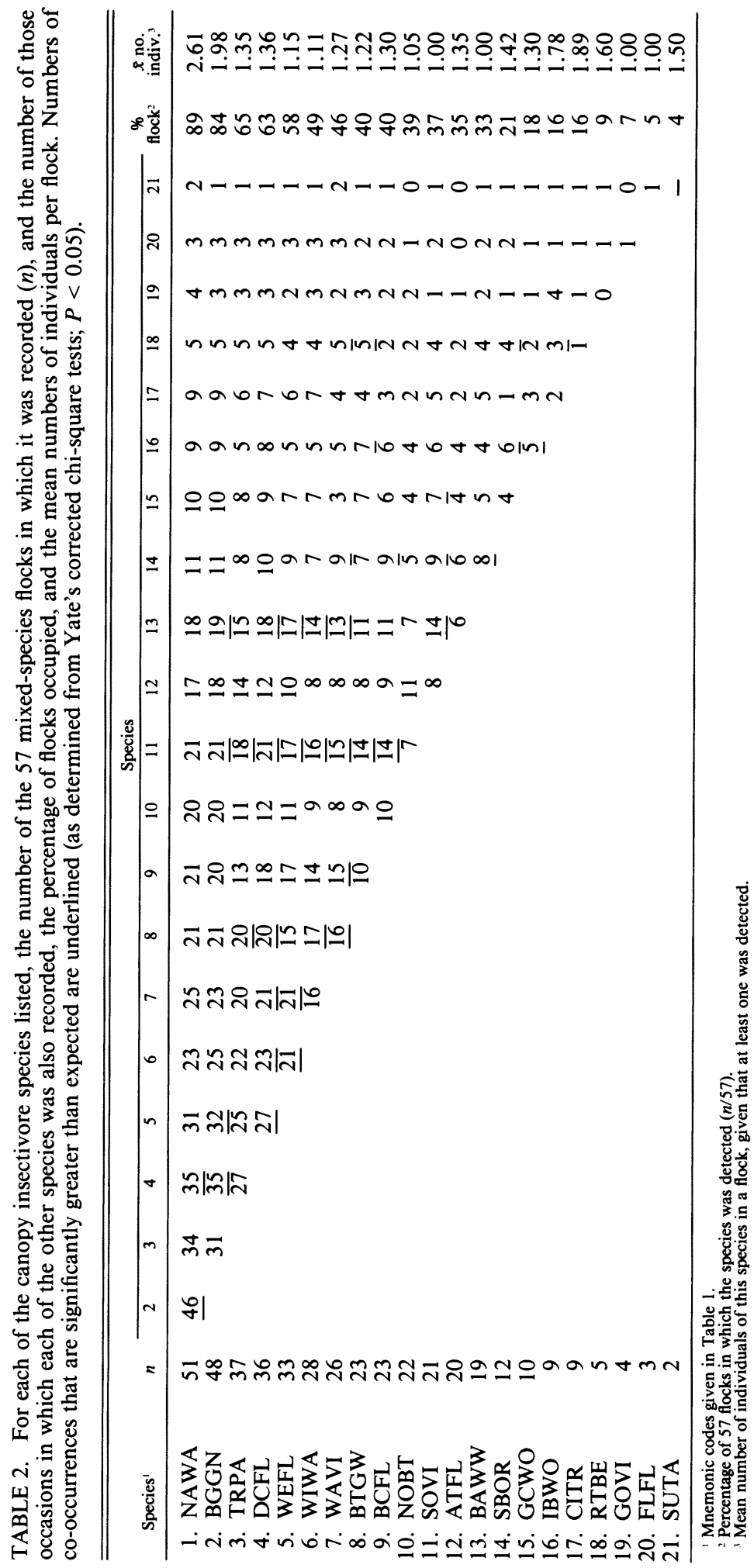




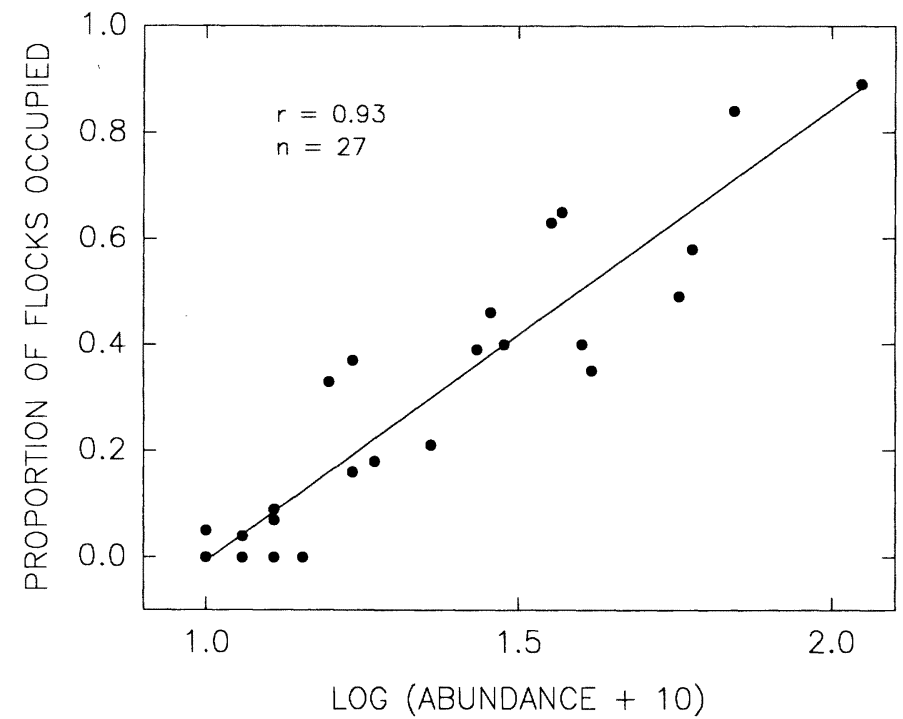

FIGURE 2. Proportion of 57 flocks occupied by each of the canopy insectivore species as a function of its absolute abundance within the study area. Abundance is defined as the mean number of birds detected per point count $(\times 100)$.

a large number of flocks. The Nashville Warbler (Vermivora ruficapilla) and Blue-gray Gnatcatcher (Polioptila caerulea) not only had a high propensity to flock (Table 1), but were the two most regular participants; each was detected in greater than $80 \%$ of the flocks (Table 2). The Nashville Warbler and Blue-gray Gnatcatcher were also intraspecifically gregarious, as evidenced by frequent vocalizations and obvious intraspecific joining and following behavior. Their gregariousness is also reflected in mean numbers of individuals per flock that were larger than those of the other participant species (Table 2).

Particular species pairs could have been associated more (or less) often than expected if they participated independently of one another. For example, if each of two species participated in half the flocks and they participated independently of one another, we would expect them to have occurred together in one-fourth of the flocks. Of the 210 possible pairwise comparisons among the 21 species, there were 40 significant positive associations and no significant negative associations (Table 2). Thus, no two species appeared to be avoiding each other at this level of spatial resolution. Instead, many of these flocking species occurred with other species more than expected if they joined flocks independently of one another. (With 210 independent tests of association, we would expect only 11 to be significant simply due to chance.) This result is similar to that reported by Jones (1977) and Powell (1979), who each found that greater than $90 \%$ of the associations in their Central American flocks were positive. In contrast, Bell $(1980,1983)$ found the number of significant associations among New Guinea flock participants to be few-no more than would be expected due to chance.

Each flock occurred in one of two easily recognized habitat "types" (moist washes and dry hillsides). Roughly $60 \%$ of the flocks that I observed were located on dry hillsides and all but four species (Flammulated Flycatcher [Deltarhynchus flammulatus], Solitary Vireo [Vireo solitarius], Black-and-white Warbler [Mniotilta varia], and Wilson's Warbler [Wilsonia pusilla]) were equally likely to be detected in hillside and wash flocks (Table 3). Each of the four nonrandomly distributed species occurred in relatively more wash and fewer hillside flocks than expected.

The average species richness of flocks occupied by nearly half of the canopy insectivore species was significantly greater than the overall mean richness of 7.7 species per flock, and no species participated in a series of flocks that averaged fewer than the overall mean number of participant species (Table 3). In other words, most species were detected in small flocks some of the time, but no species occurred exclusively in small flocks.

I recorded the presence of "close" neighbors 
TABLE 3. The distribution of occurrences between two types of habitat (dry hillsides and moist washes), and the mean species richness of flocks occupied by each of the 21 species detected in canopy insectivore flocks.

\begin{tabular}{|c|c|c|c|c|c|}
\hline \multirow[b]{2}{*}{ Species' } & \multicolumn{2}{|c|}{ Flock type } & \multirow[b]{2}{*}{$G^{2}$} & \multirow{2}{*}{$\begin{array}{c}\text { Mean species } \\
\text { richness }( \pm \mathrm{SE})\end{array}$} & \multirow[b]{2}{*}{$t^{3}$} \\
\hline & Dry hill & Moist wash & & & \\
\hline Citreoline Trogon & 3 & 6 & NS & $9.8(1.2)$ & NS \\
\hline Golden-cheeked Woodpecker & 6 & 4 & NS & $11.4(1.2)$ & $*$ \\
\hline Ivory-billed Woodcreeper & 5 & 4 & NS & $11.6(1.4)$ & $*$ \\
\hline Northern Beardless-Tyrannulet & 15 & 7 & NS & $8.0(0.9)$ & NS \\
\hline Western Flycatcher & 14 & 19 & NS & $9.5(0.6)$ & $*$ \\
\hline Dusky-capped Flycatcher & 18 & 18 & NS & $9.7(0.5)$ & $*$ \\
\hline Ash-throated Flycatcher & 15 & 5 & NS & $8.4(0.8)$ & NS \\
\hline Brown-crested Flycatcher & 11 & 12 & NS & $9.8(0.8)$ & $*$ \\
\hline Flammulated Flycatcher & 0 & 3 & $*$ & $13.7(2.4)$ & $*$ \\
\hline Rose-throated Becard & 1 & 4 & NS & $13.6(1.9)$ & $*$ \\
\hline Blue-gray Gnatcatcher & 27 & 21 & NS & $8.5(0.5)$ & NS \\
\hline Solitary Vireo & 7 & 14 & $*$ & $11.5(0.8)$ & $*$ \\
\hline Golden Vireo & 2 & 2 & NS & $9.8(2.5)$ & NS \\
\hline Warbling Vireo & 11 & 15 & NS & $10.0(0.7)$ & $*$ \\
\hline Nashville Warbler & 31 & 20 & NS & $8.1(0.5)$ & NS \\
\hline Tropical Parula & 20 & 17 & NS & $8.8(0.7)$ & NS \\
\hline Black-throated Gray Warbler & 10 & 13 & NS & $10.4(0.8)$ & $*$ \\
\hline Black-and-white Warbler & 6 & 13 & $*$ & $11.2(0.8)$ & * \\
\hline Wilson's Warbler & 10 & 18 & $*$ & $9.8(0.7)$ & $*$ \\
\hline Summer Tanager & 1 & 1 & NS & $10.5(6.5)$ & NS \\
\hline Streak-backed Oriole & 6 & 6 & NS & $11.7(1.2)$ & $*$ \\
\hline All flocks & 35 & 22 & - & $7.7(0.5)$ & - \\
\hline
\end{tabular}

Scientific names given in Table 1

Asterisk indicates a distribution that differs significantly from that of all flocks combined (G-tests with Williams' correction; $P<0.05$ ).

"Asterisk indicates a mean species richness that differs significantly from the grand mean based on all 57 flocks $(t$-tests; $P<0.05)$.

(individuals foraging less than $3 \mathrm{~m}$ from a focal bird) for a series of 13 species and found that those species were equally likely to have another bird foraging nearby (Table 4). The identity of those neighbors, however, varied significantly among five of the more common species (Table 5). The close neighbors of Blue-gray Gnatcatcher and Nashville Warbler were no different from those expected on the basis of proportions derived from point count data. In contrast, the Dusky-capped Flycatcher Myiarchus tuberculifer) and Black-throated Gray Warbler (Dendroica nigrescens) had each other as close neighbors more than expected due to chance, and the Warbling Vireo (Vireo gilvus) had other Warbling Vireos nearby more than expected.

\section{DISCUSSION}

\section{THE STRUCTURE AND ORGANIZATION OF FLOCKS}

Because many canopy insectivore species participate in mixed-species flocks all the time, and all of them participate more than $50 \%$ of the time, flocking behavior is an important part of their nonbreeding biology. As Powell (1985) pointed out, however, we need more information on the structure, dynamics, and spatial organization of mixed-species flocks if we hope to gain a better understanding of the evolutionary significance of flocking behavior.

In terms of the structure and spatial organization of Chamela flocks, how do we interpret

TABLE 4. For each of several species, the number of times a flocking individual was observed to have another flock participant within 2-3 m. The distribution of occurrences with and without close neighbors does not differ significantly among species (using the species for which there were $\geq 5$ observations, $G=11.3$; NS).

\begin{tabular}{lrc}
\hline \hline \multicolumn{1}{c}{ Species' } & $\begin{array}{c}\text { With } \\
\text { close } \\
\text { neighbor }\end{array}$ & $\begin{array}{c}\text { Without } \\
\text { close } \\
\text { neighbor }\end{array}$ \\
\hline Northern Beardless-Tyrannulet & 2 & 0 \\
Western Flycatcher & 0 & 4 \\
Dusky-capped Flycatcher & 17 & 1 \\
Ash-throated Flycatcher & 0 & 1 \\
Brown-crested Flycatcher & 1 & 0 \\
Blue-gray Gnatcatcher & 23 & 5 \\
Solitary Vireo & 6 & 2 \\
Warbling Vireo & 16 & 2 \\
Nashville Warbler & 52 & 7 \\
Tropical Parula & 9 & 6 \\
Black-throated Gray Warbler & 13 & 4 \\
Black-and-white Warbler & 9 & 0 \\
Wilson's Warbler & 1 & 1 \\
\hline
\end{tabular}

Scientific names given in Table 1. 
TABLE 5. Values indicate the number of times a particular species was observed as a close neighbor of the species on the left. The identity of near neighbors differs significantly among species $(G=78.1 ; P<0.001)$.

\begin{tabular}{|c|c|c|c|c|c|c|c|c|}
\hline \multirow[b]{2}{*}{ Focal species' } & \multirow[b]{2}{*}{$n$} & \multicolumn{6}{|c|}{ Neighboring species } & \multirow[b]{2}{*}{$P^{2}$} \\
\hline & & $\overline{\mathrm{DCFL}}$ & BGGN & WAVI & NAWA & BTGW & Other & \\
\hline Dusky-capped Flycatcher (DCFL) & 17 & 0 & 4 & 0 & 4 & 7 & 2 & 0.040 \\
\hline Blue-gray Gnatcatcher (BGGN) & 23 & 4 & 2 & 0 & 9 & 1 & 7 & 0.564 \\
\hline Warbling Vireo (WAVI) & 16 & 0 & 0 & 10 & 4 & 0 & 2 & 0.001 \\
\hline Nashville Warbler (NAWA) & 52 & 4 & 9 & 4 & 18 & 2 & 15 & 0.988 \\
\hline Black-throated Gray Warbler (BTGW) & 13 & 7 & 1 & 0 & 2 & 0 & 3 & 0.048 \\
\hline
\end{tabular}

' Scientific names given in Table 1.

From $G$-test, with expected numbers based on the proportions derived from point count data.

the presence of a larger than expected number of positive associations and the absence of negative associations among flock participants? The positive associations could result from either of two phenomena: (1) two species interact in some way, and at least one member of the species-pair is more likely to join if the other is present; or (2) the association is an indirect consequence of two species being restricted to the same part(s) of the study area. In the latter case, participation by some species would be restricted to the subset of flocks that occurred in, say, a particular habitat type, and the positive association between a pair of those species would be a reflection of their similarity in habitat use.

Unfortunately, mutual habitat dependency may be difficult to recognize because it requires knowledge of the habitat parameters that two species might be co-dependent upon. Nonetheless, as an attempt to test the importance of mutual habitat dependencies, I divided the flock data into two sets, which corresponded with two habitat "types" (moist washes vs. dry hillsides). Four species used the wash habitat more than expected on the basis of the number of flocks detected in each habitat. The significant positive associations recorded among Solitary Vireo, Black-and-white Warbler, and Wilson's Warbler could, indeed, have been a product of their similar, nonrandom distribution between the wash and dry-hillside habitat types. That particular habitat restriction can account for only three of the 40 significant positive associations, however. Thus, unless the other positively associated pairs are similarly but independently restricted to within-forest habitat patches that are not readily apparent to me, it is likely that the positive associations are due, instead, to either mutual or one-sided species' dependencies.

An absolute dependency would require one species to be present in the flock before its associate was able to join. It is noteworthy that only 5 of the 40 significant positive associations involved a one-sided conditional probability where one species was always present, given the other; in all other instances, each species occurred in the absence of the other at least some of the time (Table 2). The positive associations do not, therefore, result from species being absolutely dependent on the presence of others before they join.

Is there an identifiable core or nucleus of intraspecifically social species in these flocks? In Moynihan's (1962) original terminology, a nuclear species is one that is capable of influencing the formation and cohesion of flocks; they are the species around which foraging activity is organized. In a quantitative sense, nuclear species can be identified using the following criteria: (1) they are joined and followed more often than they themselves join and follow others (Moynihan 1962, Munn and Terborgh 1979). Consequently, they tend to be positioned in the front of flocks (Rand 1954, Greig-Smith 1978); (2) they are intraspecifically gregarious and are rarely, if ever, seen away from other individuals of their own species. As a result, they are virtually always seen in flocks (have a strong "flocking propensity"), and they tend to be relatively numerous, averaging a greater number of individuals per species than any of the other flock participants (Winterbottom 1943, 1949; Rand 1954; Short 1961; Moynihan 1962; Austin and Smith 1972; Chipley 1977; Greig-Smith 1978; Munn and Terborgh 1979; Bell 1980, 1983; Powell 1985); (3) they are "regular" participants of mixed-species flocks i.e., most flocks include these species (McClure 1967, Greig-Smith 1978, Powell 1979, Bell 1980); (4) they are conspicuous by their plumage coloration, the near-continuous nature 
of their calls, and/or their active behavior (Moynihan 1962, Austin and Smith 1972, Chipley 1977, Greig-Smith 1978, Munn and Terborgh 1979, Powell 1985); (5) they are year-round residents (Austin and Smith 1972, Bell 1983).

Although they do not meet the last criterion, the following data support the notion that the Nashville Warbler and Blue-gray Gnatcatcher serve as nuclear species in the tropical deciduous forest flocks of Chamela: (1) these two species are intraspecifically social, and averaged the largest numbers of individuals per species while in flocks. Each could also be found foraging in monospecific groups and, while the intraspecific group size may not have been large, I rarely saw individuals of either species foraging alone. They showed clear evidence of joining and following one another, and vocalized with chips or buzzes frequently; (2) they were regular flock participants. Each occurred in greater than $84 \%$ of all flocks encountered, and one or the other was present in $93 \%$ of the flocks; (3) although most species do not appear to be absolutely dependent on the presence of another species before they will join a flock, most species (18 of 21) had a least one other species present more than $90 \%$ of the time. The most frequent associate of every one of those 18 species was either Nashville Warbler or Blue-gray Gnatcatcher (Table 2). Moreover, the mean probability that either a Nashville Warbler or Blue-gray Gnatcatcher would be present, given an individual of any other species, was 0.95 and 0.91 , respectively (based on data in Table 2); and (4) they were conspicuous in their movements and calls, and often provided the first indication of the presence of a flock.

Even though a species can be classified as a nuclear species according to objective data such as these, what does this mean in terms of the behavior of flock participants? Are nuclear species really needed for the formation of flocks and for the maintenance of their cohesion, as implied by Moynihan's (1962) original qualitative definition? Data on flock composition from this and other studies show that intraspecifically social, nuclear species are usually, but not necessarily, present. In the strictest sense, then, nuclear species are probably not needed for flock formation. On the other hand, nuclear species may be necessary for the maintenance of flock cohesion. The latter possibility is supported by the observation that flocks without nuclear species break apart rapidly (Vuilleumier 1970, Powell 1979, person- al observation). The attraction of nuclear species may be nothing more than that they provide a sharp focus for movement and direction (Austin and Smith 1972), which results from the conspicuousness of a number of active, vocal individuals foraging in close proximity.

In all but one instance of which I am aware (Greenberg 1984), mixed-species flocking species that have been labeled nuclear have been residents. Powell $(1979,1980)$ states that it is possible to find mixed-species flocks composed entirely of migratory species, but actual flock composition data were not presented. Ewert and Askins (1991) described flocks on the Virgin Islands that were composed almost entirely of migratory warblers, but the abundant Bananaquit (Coereba flaveola) may still have acted as the nucleus of those flocks. In general, migrants comprise a minor component of mixed-species flocks (Powell 1980). It is remarkable, then, that as many as one half the participant species, including both Nashville Warbler and (probably) Blue-gray Gnatcatcher, are long-distance neotropical migrants (see Appendix I). This makes the organization of these particular flocks unique, and adds to the ornithological uniqueness of western Mexico in winter (Hutto, in press).

Aside from the nuclear species, there may be some sort of incidence function for each of the other species, such that they occur only within a limited range of flock sizes. Is there evidence that some species are small-flock specialists and others large-flock specialists? Defining a small flock as one that had fewer than six participants $(N=$ 21 ), the number of small flocks that a species participated in could be predicted from the total number of flocks in which it was recorded $(r=$ $0.88, P<0.001)$ or from its abundance $(r=0.90$, $P<0.001)$. Thus, small flocks appear to be randomly composed subsets of available individuals, and no species was restricted to small flocks (the average flock size of no species was less than the overall average). In contrast, a few species might qualify as large-flock specialists because, in general, the fewer the number of flocks a species participated in, the larger its average flock size $(r=-0.68, P<0.001)$. This same trend was reported by Chipley (1977) and Cieślak (1983) and would be predicted if either a "core" or "nucleus" of usual participants existed and infrequent attendants were usually additions onto that core, or if infrequent attendants participated only in flocks that exceeded some minimum size. 
Otherwise, those species that occurred in only a few flocks would be expected to occur in some small and some large flocks, and their flock sizes should be no different from the overall average.

Do some species really need large flocks to join, or is that pattern a consequence of the fact that they are patchily distributed and merely occasional "add-ons" to a usually-present core? To answer this, we must know whether small flocks per se are avoided. All but one of the 10 most infrequent participant species were recorded in at least one flock of less-than-average richness, and six occurred in flocks of five species or fewer (see Appendix I). Therefore, small flocks are probably not actively avoided by any species. Rather, the infrequent participants are probably restricted in distribution relative to the more regular participants. They will, on average, be additions to an existing core and, therefore, occur in richer-than-average flocks. The restriction of some species to the moister wash habitats, for example, was responsible for the richer-than-average flocks that occurred there (the mean number of species in hillside flocks was 6.2 , in comparison with a mean of 10.1 for flocks in washes; $t=4.23, \mathrm{df}=55, P<0.001)$. Thus, except for the presence of a well-defined nucleus, other participants appear to be collections of whichever species happen to co-occur within the "home range" of the nuclear species.

\section{THE SELECTIVE ADVANTAGES}

\section{OF FLOCKING}

One potential feeding benefit associated with flock foraging is that an individual within a group may discover and use widely scattered, patchily distributed food more efficiently than if it foraged independently. This kind of benefit may accrue frugivores that flock, but is unlikely to apply to insectivorous birds, which move more-or-less continuously through the woods (Krebs et al. 1972). Instead, potential feeding benefits are probably derived from use of insects that are flushed by flockmates or from copying the behavior of others. In either case, the presence of just any species as a flockmate would not be satisfactory; a species would probably require the presence and close proximity of another species that employed a specific kind of foraging behavior (much more specific than "insectivorous" behavior). In contrast, because warnings about the presence or approach of avian predators come primarily from auditory cues (Sullivan 1984, 1985), birds can reap the benefits of early warn- ing through association with virtually any other species and without a highly structured spatial organization within the flock.

Is the spatial organization among and within the mixed-species flocks I observed more consistent with the nonrandomness expected if feeding benefits were the primary selective advantage of flocking, or more consistent with a loose spatial organization that might be expected if predator protection were the primary selective advantage? The independent associations of most pairs of species among flocks suggests the latter as a generalization, while the 40 habitat-independent, positive associations among species suggests that at least some may join flocks to gain feeding benefits. If the positive associations result from at least one member of a species pair gaining feeding benefits from the other, the same pairs should also have occurred as close associates more often than expected. Indeed, the Duskycapped Flycatcher and Black-throated Gray Warbler co-occurred in flocks more than expected (Table 2) and were also each other's close neighbors more often than expected (Table 5). Because the behaviors of these species are quite different, however (flycatching vs. gleaning), it is unclear what the benefit might be unless the flycatcher benefits from insects flushed by the warbler. Interestingly, the flycatcher was often present (in 14 flocks) without the warbler, which diminishes the likelihood of an obligate relationship. Warbling Vireos were each other's neighbors more than expected, but there were not always two or more present in a flock (the mean number of Warbling Vireos per flock was 1.27; Table 2). Close neighbors of the two nuclear species (Blue-gray Gnatcatcher and Nashville Warbler) were no different from those expected on the basis of the relative abundance of species. If species are gaining feeding benefits from flocking, they are not doing so by using the same close neighbor because the distribution of neighbors differed significantly among the five species (Table 5).

The patterns of association could also result from adjustments of some species to minimize the cost of foraging in a flock. Specifically, flocking could have a detrimental (rather than beneficial) effect on the foraging behavior of participants because flockmates could decrease each other's chance of capturing prey. If so, the effects of such competition for food are not mitigated in the present situation by selective avoidance of flocks with competitors. This is clear from the 
lack of negative associations among flocking species. Instead, smaller-scale patterns in the use of space or in foraging tactics may be the primary mechanism of mitigating such competition, if it exists (Hutto 1988). Whether the patterns of close association reflect efforts by some species to avoid competition is unknown.

Several lines of evidence suggest that, aside from the nearly ever-present nuclear species, these flocks are variable collections of whatever canopy insectivore species occur in the same area: (1) the probability of occurrence in a flock can be accurately predicted from a species' abundance, (2) most species are distributed independently of one another among flocks, and (3) only a few of the significant positive associations resulted from one species always being present, given the other. These flocks are not mutually integrated functional units that require a partic. $\rightarrow$ ular membership in order to exist. Nonetheless, these and other mixed-species flocks may need one or more intraspecifically gregarious, nuclear species to maintain flock cohesion and structure (Bell 1983).

This leaves us with the question of what sort of benefit a variety of attendant species can ac crue from a predictable set of nuclear species plus a compositionally less predictable group of other attendant species. I suggest that predator protection is much more likely than foraging enhancement to be such a benefit, at least for most spe - $\rightarrow$ cies. For some species, however, the close associations of some attendants with a nonran dom subset of other attendant species may reflect a spatial organization that has evolved in response to additional feeding costs or benefits $\rightarrow$ Moreover, the costs and benefits associated with flocking are likely to differ among species, as implied by the significant difference in the identity of close associates among participant species (see also Moynihan 1962, Croxall 1976, MacDonald and Henderson 1977). Only through a more thorough study that couples behavioral observation of interactions with spatial associations of participants can we come to understand the particular costs and benefits of flocking for any single species and, therefore, the evolutionary reasons for flocking behavior.

\section{ACKNOWLEDGMENTS}

I am grateful to the World Wildlife Fund-U.S., Smith $\rightarrow$ sonian Institution, and University of Montana for financial support. Research facilities at the Estación de Biología Chamela were provided by the Universidac -
Nacional Autónoma de México. I would also like to thank Steve Bullock and the rest of the staff at Chamela for logistical support, and Laura Márquez Valdelamar for assistance in the field. Finally, I am grateful to Jeff Brawn, Russ Greenberg, Erick Greene, and anonymous reviewers who provided comments that helped clarify my thinking on numerous points.

\section{LITERATURE CITED}

Alatalo, R. V., D. Eriksson, L. Gustafsson, and K. LARSSON. 1987. Exploitation competition influences the use of foraging sites by tits: experimental evidence. Ecology 68:284-290.

Austin, G. T., ANd E. L. Smith. 1972. Winter foraging ecology of mixed insectivorous bird flocks in oak woodland in southern Arizona. Condor 74: 17-24.

Bell, H. L. 1980. Composition and seasonality of mixed-species feeding flocks of insectivorous birds in the Australian Capital Territory. Emu 80:227232.

BeLl, H. L. 1983. A bird community of lowland rainforest in New Guinea. 5. Mixed-species feeding flocks. Emu 82:256-275.

Chipley, R. M. 1977. The impact of wintering migrant wood warblers on resident insectivorous passerines in a subtropical Colombian oak woods. Living Bird 15:119-141.

Cieślak, M. 1983. Heterospecific winter flocks of birds in a pine forest. Ekol. Pol. 31:219-234.

Croxall, J. P. 1976. The composition and behavior of some mixed-species bird flocks in Sarawak. Ibis 118:333-346.

Ekman, J. 1987. Exposure and time use in Willow Tit flocks: the cost of subordination. Anim. Behav. 35:445-452.

Ekman, J. 1989. Ecology of non-breeding social systems of Parus. Wilson Bull. 101:263-288.

Ekman, J. 1990. Alliances in winter flocks of Willow Tits: effects of rank on survival and reproductive success in male-female associations. Behav. Ecol. Sociobiol. 26:239-245.

Ekman, J., AND M. HAKe. 1988. Avian flocking reduces starvation risk: an experimental demonstration. Behav. Ecol. Sociobiol. 22:91-94.

Elgar, M. A. 1989. Predator vigilance and group size in mammals and birds: a critical review of the empirical evidence. Biol. Rev. 64:13-33.

Ewert, D. N., AND R. A. Askins. 1991. Flocking behavior of migratory warblers in winter in the Virgin Islands. Condor 93:864-868.

GadDIs, P. K. 1983. Composition and behavior of mixed-species flocks of forest birds in north-central Florida. Fl. Field Nat. 11:25-34.

GREENBERG, R. 1984. The winter exploitation systems of Bay-breasted and Chestnut-sided Warblers in Panama. Univ. Calif. Publ. Zool. 116:1-107.

$\rightarrow$ Greig-Smith, P. W. 1978. The formation, structure and function of mixed-species insectivorous bird flocks in west African savanna woodland. Ibis 120: 284-297.

GuSTAFsSON, L. 1988. Foraging behavior of individual Coal Tits, Parus ater, in relation to their age, sex and morphology. Anim. Behav. 36:696-704.

Herrera, C. M. 1979. Ecological aspects of hetero- 
specific flock formation in a Mediterranean passerine bird community. Oikos 33:85-96.

$\rightarrow$ Hogstad, O. 1988a. Social rank and antipredator behaviour of Willow Tits Parus montanus in winter flocks. Ibis 130:45-56.

$\rightarrow$ Hogstad, O. 1988b. Advantages of social foraging of Willow Tits Parus montanus. Ibis 130:275-283.

$\rightarrow$ Hogstad, O. 1989. Subordination in mixed-age bird flocks-a removal study. Ibis 131:128-134.

HutTo, R. L. 1980. Winter habitat distribution of migratory land birds in western Mexico, with special reference to small, foliage-gleaning insectivores, p. 181-203. In A. Keast and E. S. Morton [eds.], Migrant birds in the Neotropics. Smithsonian Institution Press, Washington, DC.

Hutto, R. L. 1987. A description of mixed-species insectivorous bird flocks in western Mexico. Condor 89:282-292.

$\rightarrow$ Hutтo, R. L. 1988. Foraging behavior patterns suggest a possible cost associated with participation in mixed-species bird flocks. Oikos 51:79-83.

Hutto, R. L. In press. Some ornithologically unique aspects of western Mexico. In G. Ceballos and D. Navarro [eds.], Endangered vertebrates of Mexico.

Hutto, R. L., P. Hendricks, And S. Pletschet. 1985. Un censo invernal de las aves de la Estación de Biología Chamela, Jalisco México. An. Inst. Biol. Univ. Nat. Autón. Méx. 56:945-954.

$\rightarrow$ Hutto, R. L., S. M. Pletschet, And P. Hendricks $\rightarrow$ 1986. A fixed-radius point count method for nonbreeding and breeding season use. Auk 103:593602.

$\rightarrow$ Jones, S. E. 1977. Coexistence in mixed species antwren flocks. Oikos 29:366-375.

$\rightarrow$ KREBS, J. R. 1973. Social learning and the adaptiv $\rightarrow$ significance of mixed-species flocks of chickadees. Can. J. Zool. 51:1275-1288.

$\rightarrow$ Krebs, J. R., M. H. MacRoberts, ANd J. M. Cullen $\rightarrow$ 1972. Flocking and feeding in the Great Tit, Parus major-an experimental study. Ibis 114:507-530.

$\rightarrow$ Lima, S. L. 1985. Maximizing feeding efficiency and minimizing time exposed to predators: a trade-off in the Black-capped Chickadee. Oecologia 66:6067.

LINDSTRÖM, А. 1989. Finch flock size and risk of hawk predation at a migratory stopover site. Auk 106:225-232.

MacDonald, D. W., and D. G. Henderson. 1977. Aspects of the behaviour and ecology of mixedspecies bird flocks in Kashmir. Ibis 119:481-491.

MCCLuRE, H. E. 1967. The composition of mixer $\rightarrow$ species flocks in lowland and sub-montane forests of Malaya. Wilson Bull. 79:130-154.

MORSE, D. H. 1970. Ecological aspects of some mixedspecies flocks of birds. Ecol. Monogr. 40:1 19-168.

MoRSE, D. H. 1977 . Feeding behavior and predator avoidance in heterospecific groups. BioScience 27 332-339.

Moynihan, M. 1962. The organization and probable evolution of some mixed species flocks of Neotropical birds. Smithsonian Misc. Collect. 143:1140.

Munn, C. A., And J. W. Terborgh. 1979. Multispecies territoriality in Neotropical foraging flocks. Condor 81:338-347.

Petit, D. R., And K. L. Bildstein. 1987. Effect of group size and location within the group on the foraging behavior of White Ibises. Condor 89:602609.

PopP, J. W. 1988. Scanning behavior of finches in mixed-species groups. Condor 90:510-512.

Powell, G.V.N. 1979. Structure and dynamics of interspecific flocks in a Neotropical mid-elevation forest. Auk 96:375-390.

Powell, G.V.N. 1980. Migrant participation in Neotropical mixed species flocks, p. 477-483. In A. Keast and E. S. Morton [eds.], Migrant birds in the Neotropics. Smithsonian Institution Press, Washington, DC.

Powell, G.V.N. 1985. Sociobiology and the adaptive significance of interspecific foraging flocks in the Neotropics. Ornith. Monogr. 36:713-732.

RAND, A. L. 1954. Social feeding behavior of birds. Fieldiana: Zool. 36:1-71.

SHORT, L. L., JR. 1961. Interspecies flocking of birds of montane forest in Oaxaca, Mexico. Wilson Bull. 73:341-347.

Sullivan, K. A. 1984. The advantage of social foraging in Downy Woodpeckers. Anim. Behav. 32: 16-22.

Sullivan, K. 1985. Selective alarm calling by Downy Woodpeckers in mixed-species flocks. Auk 102: 184-187.

Székely, T., T. Szép, ANd T. Juhász. 1989. Mixed species flocking of tits (Parus spp.): a field experiment. Oecologia 78:490-495.

VALBURG, L. K. 1992. Flocking and frugivory: the effect of social groupings on resource use in the Common Bush-Tanager. Condor 94:358-363.

VAN Buskirk, J., AND D. C. SMITH. 1989. Individual variation in winter foraging of Black-capped Chickadees. Behav. Ecol. Sociobiol. 24:257-263.

Vuilleumier, F. 1970. L'organisation sociale des bandes vagabondes d'oiseaux dans les Andes du Pérou central. Revue Suisse de Zoologie 77:209235.

Winterbottom, J. M. 1943. On woodland bird parties in northern Rhodesia. Ibis 85:437-442.

WinterbotTom, J. M. 1949. Mixed bird parties in the tropics, with special reference to northern Rhodesia. Auk 66:258-263. 


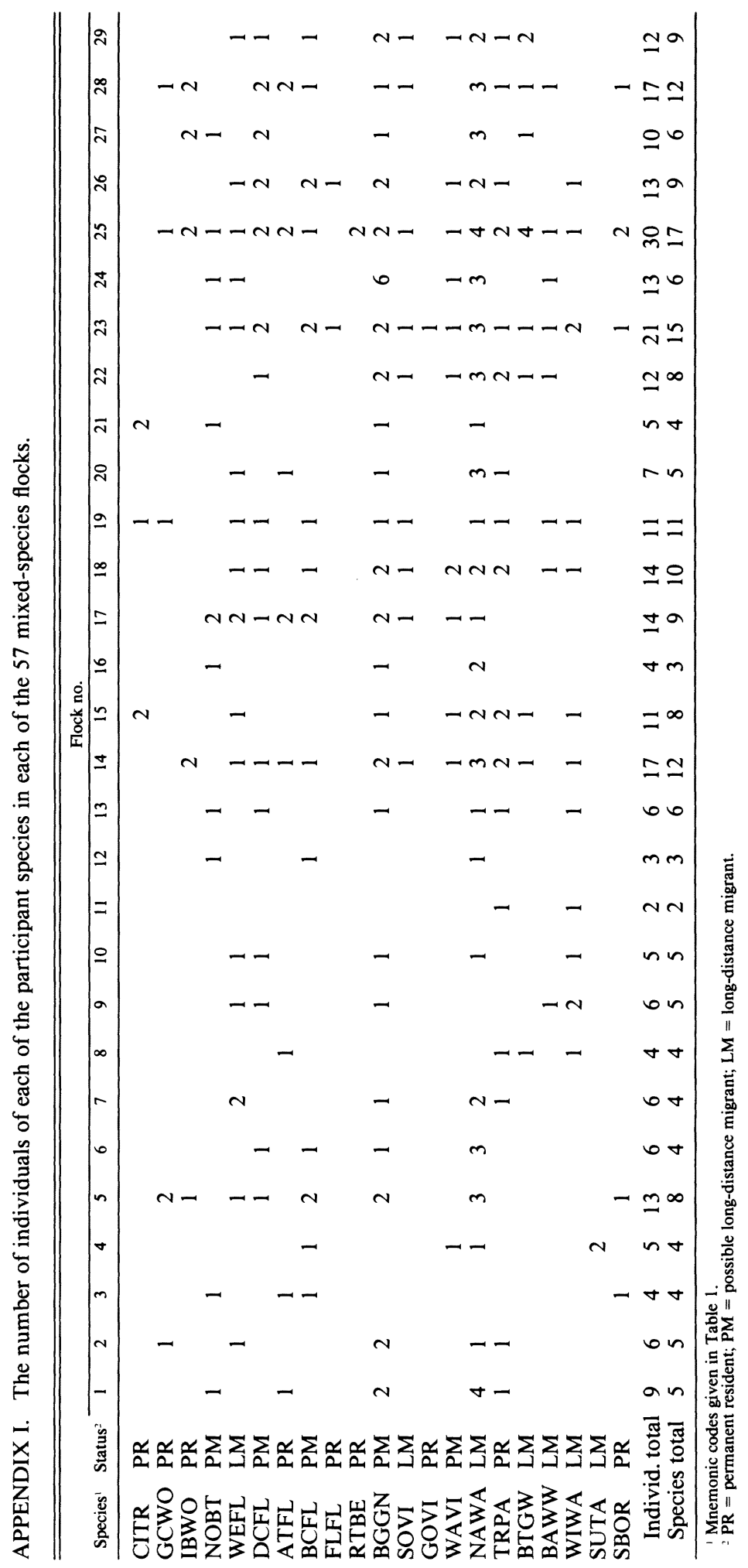




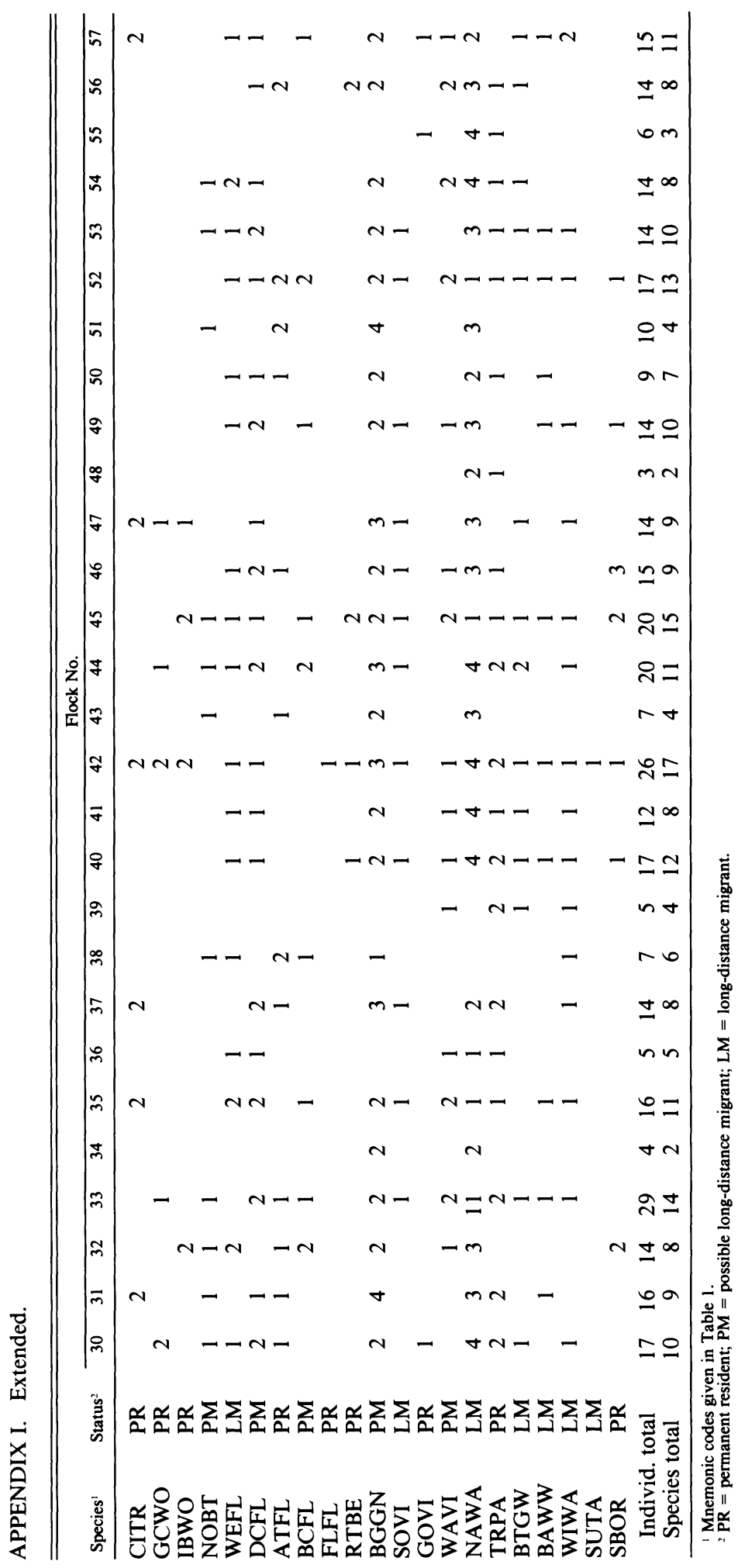

